\title{
O ENSINO DE GEOMETRIA NUMA PERSPECTIVA INTERDISCIPLINAR COMO INICIATIVA PARA UMA ABORDAGEM TRANSDISCIPLINAR
}

\footnotetext{
M. ARCANJO FILHO' e A. H. C. TAVARES
1Aluno do Curso de Especialização em Língua Portuguesa e Matemática numa perspectiva Transdisciplinar
2Professor do Instituto Federal do Rio Grande do Norte (IFRN) - Campus Natal Zona Norte
miguelfilhoorg@hotmail.com² - agamenon.tavares@ifrn.edu.br²

Artigo submetido em abril/2011 e aceito em abril/2011

DOI: $10.15628 /$ rbept.2011.3178
}

\section{RESUMO}

O presente trabalho visa refletir sobre as contribuições que a interdisciplinaridade e a transdisciplinaridade podem deixar para o ensino de Matemática, mais precisamente de Geometria, tendo em vista as dificuldades que os professores da Educação Básica encontram para ensinar este assunto. Nesse sentido pretende-se inicialmente, mostrar que é plenamente possível trabalhar o referido tema de forma interdisciplinar, ou seja, abordá-lo através das diferentes disciplinas Matemática, Geografia, Língua Portuguesa, etc. para depois, partindo desse projeto em conjunto, chegar à transdisciplinaridade. Assim, quer-se demonstrar que o ensino de Geometria mediante a visão interdisciplinar pode culminar num ensino numa perspectiva transdisciplinar.

PALAVRAS-CHAVE: Geometria, interdisciplinaridade, transdisciplinaridade.

\section{THE TEACHING OF GEOMETRY PERSPECTIVE INITIATIVE AS INTERDISCIPLINARY APPROACH TRANSDISCIPLINARY}

\begin{abstract}
This paper aims to reflect on the contributions that interdisciplinarity and transdisciplinarity can leave for teaching mathematics, more precisely Geometry, given the difficulties that teachers of basic education are to teach this subject. In this sense we intend to initially show that it is fully possible to work the said topic in an interdisciplinary manner, ie, approaching it through the
\end{abstract}

different disciplines Mathematics, Geography, English Language, etc for after starting this project come together transdisciplinarity. So, you want to demonstrate that teaching geometry through interdisciplinary vision can culminate in teaching a cross-disciplinary perspective.

KEYWORDS: Geometry, interdisciplinarity, transdisciplinarity. 


\section{INTRODUÇÃO}

O ensino de Matemática na Educação Básica tem como um de seus muitos objetivos proporcionar aos alunos o desenvolvimento do raciocínio lógico, das habilidades cognitivas e a capacidade de resolver problemas, sendo assim uma disciplina de relevante importância para todas as pessoas. No entanto, historicamente, a Matemática é vista como uma disciplina difícil de ser entendida, com altos índices de reprovação e pouco interessante, sendo que dentre as três áreas básicas dessa ciência Aritmética, Álgebra e Geometria, esta ultima é uma das que mais sofre rejeição quanto ao ensino por parte dos professores e quanto à aprendizagem por parte dos alunos, de modo que em muitas escolas os conteúdos referentes ao estudo de Geometria sequer são ministrados em sala de aula.

A fim de mudar tal realidade, propõe-se neste trabalho mostrar que através do ensino na perspectiva interdisciplinar é possível melhorar o processo ensino-aprendizagem de Geometria na escola, isso por que o ensino mediante essa visão pedagógica torna-se mais atrativo e interessante. Pretende-se tambem comprovar que a partir de um ensino na perspectiva interdisciplinar pode-se chegar na tão sonhável transdisciplinaridade. Para fundamentar esta proposta, far-se-á um levantamento bibliográfico usando-se as ideias de Lorenzato (1995), D'Ambrosio (1997), Morin (2003), Sommerman (2006), entre outros autores que afirmam ser a interdisciplinaridade e quando possível a transdisciplinaridade caminhos para uma educação melhor, analisando as dificuldades e possibilidades de adotar-se essas estratégias de ensino no dia a dia pedagógico dos professores. Além disso, analisar-se-á os resultados de uma pesquisa de campo realizada com professores de Matemática para saber o que os mesmos acham dessas perspectivas pedagógicas.

Com base nisso, nosso problema de pesquisa é: Como abordar o ensino de Geometria numa perspectiva transdisciplinar partindo da interdisciplinaridade?

Assim far-se-á uma reflexão sobre os efeitos positivos que o ensino nessas perspectivas podem trazer para os alunos investigando-se maneiras de se introduzir tais práticas em sala de aula.

\section{A IMPORTÂNCIA DO ENSINO DE GEOMETRIA}

O ensino de Matemática é fundamental para todas as pessoas e, como se sabe, os conteúdos dessa disciplina são divididos em alguns grupos principais, dentre eles: Aritmética, Álgebra e Geometria. No entanto, percebe-se uma priorização por parte dos professores do ensino dos dois primeiros tópicos acima citados, enquanto que a Geometria geralmente é deixada em segundo plano. Porém, como afirmam as Orientações Curriculares Nacionais para o Ensino Médio (BRASIL, 2006, p. 75):

O estudo da Geometria deve possibilitar aos alunos o desenvolvimento da capacidade de resolver problemas práticos do quotidiano, como por exemplo, orientar-se no espaço, ler mapas, estimar e comparar distâncias percorridas, reconhecer propriedades de formas geométricas básicas, saber usar diferentes unidades de medida.

Nesse sentido, nota-se que de fato o ensino de Geometria deve acontecer em sala de aula, pois seu estudo possibilita aos alunos a capacidade de resolver inúmeros problemas do dia a dia, 
como por exemplo: As dimensões de uma piscina são $50 \mathrm{~m}$ de comprimento, $25 \mathrm{~m}$ de largura e $3 \mathrm{~m}$ de profundidade, qual o seu volume em litros? Deseja-se cimentar um quintal retangular com 10 $\mathrm{m}$ de largura e $14 \mathrm{~m}$ de comprimento, o revestimento será feito com $3 \mathrm{~cm}$ de espessura, qual o volume de cimento utilizado nesse revestimento ?

Tais situações que têm como respostas 3750000 litros e 4,2 metros cúbicos, respectivamente, confirmam a aplicabilidade da Geometria no nosso cotidiano, visto que corriqueiramente nos deparamos com os mesmos. Ainda sobre a importância do ensino da Geometria, Lorenzato $(1995$, p. 5) diz que:

Na verdade, para justificar a necessidade de ter a Geometria na escola, bastaria o
argumento de que sem estudar Geometria as pessoas não desenvolvem o pensar
geométrico ou o raciocínio visual e, sem essa habilidade, elas dificilmente
conseguirão resolver as situações de vida que forem geometrizadas; também não
poderão se utilizar da Geometria como fator altamente facilitador para a
compreensão e resolução de questões de outras áreas de conhecimento humano.
Sem conhecer Geometria a leitura interpretativa do mundo torna-se incompleta,
a comunicação das ideias fica reduzida e a visão da Matemática torna-se
distorcida.

Sendo assim, fica bastante claro que não se deve desprezar o ensino de Geometria, pelo contrário, é preciso que o mesmo seja intensificado a fim de que os alunos tenham conhecimento suficiente para resolver problemas do dia a dia. Contudo, com base no que afirma Lorenzato (1995, p. 3): "O ensino de Geometria se comparado com outras partes da matemática tem sido o mais desvairador" e completa "No Brasil, já fomos mais além: a Geometria está ausente ou quase ausente da sala de aula" e em relatos de experiências de professores da Educação Básica é notório que nossa realidade no que se refere ao ensino de Geometria está longe da desejável.

O ensino de Geometria também se justifica pelo fato dela auxiliar conteúdos de outras disciplinas, como por exemplo, leitura de mapas e interpretação de gráficos e tabelas. Como afirma Lorenzato $(1995$, p. 6):
A Geometria é um excelente apoio às outras disciplinas: como interpretar um mapa, sem o auxílio da Geometria? E um gráfico estatístico? Como compreender conceitos de medida sem ideias geométricas? A história das civilizações está repleta de exemplos ilustrando o papel fundamental da Geometria (que é carregada de imagens) teve na conquista de conhecimentos artísticos, científicos e, em especial, matemáticos.

Diante disso, fica claro que o ensino de Geometria é essencial para os alunos, de modo que é preciso encontrar estratégias que facilitem o processo ensino-aprendizagem desse ramo do conhecimento matemático, a fim de que os educandos possam apropriar-se cada vez mais do saber geométrico.

\section{O ENSINO DE GEOMETRIA NAS PERSPECTIVAS INTERDISCIPLINAR E TRANSDISCIPLINAR}

Diante da necessidade do estudo e ensino de Geometria na escola, deve-se ressaltar que é necessário para isso haver uma abordagem prática desta temática, discutindo conceitos, fórmulas 
e/ou teoremas com base nas aplicações dos mesmos na vida dos educandos. Além disso, deve haver uma interligação entre as disciplinas, ou seja, ensinar de forma interdisciplinar, visto que essa visão pedagógica busca aproximar as áreas de conhecimento uma das outras, ou seja, unificar o conhecimento através do ensino de conteúdos que são comuns a várias disciplinas. Sobre isso, Zabala (2002, p. 33) diz que a interdisciplinaridade é "a interação entre duas ou mais disciplinas, que podem implicar transferência de leis de uma disciplina a outra, originando, em alguns casos, um novo corpo disciplinar, como, por exemplo, a bioquímica ou a psicolinguística".

Historicamente, a origem do termo interdisciplinaridade é bastante controversa de maneira que há aparições do termo antes do século XX, porém sua consolidação se deu na França no ano de 1970 no I Seminário Internacional sobre a Pluridisciplinaridade e a Interdisciplinaridade (Sommerman, 2006). Ainda sobre esse aspecto histórico da interdisciplinaridade, deve-se destacar que a mesma possui raízes na História Antiga, como afirma Silva (2008, p.12): “[...] esse interesse não é novo, uma vez que encontra raízes na Grécia Antiga, nas ideias de Platão e Aristóteles. No decorrer da história, há, em determinados momentos, a busca por um saber unitário, com vistas a uma visão global do Universo".

Quanto a parte legal, a própria Lei de Diretrizes e Bases (LDB) $n^{\circ}$ 9394/96 bem como os Parâmetros Curriculares Nacionais (PCNs) "[...] recomendam como eixos centrais a interdisciplinaridade e a contextualização na organização". Esta recomendação sem dúvida devese a grande relevância e eficácia dessa estratégia pedagógica, sendo uma pena muitos educadores ainda preferirem um ensino voltado ao individualismo e ao tradicionalismo prejudicando o desempenho de seus alunos, pelo fato de não valorizarem a mesma ou por não terem conhecimento detalhado dessa visão pedagógica, pois Fazenda (2001) afirma que "muitos dizem que fazem [projetos interdisciplinares], mas poucos o fazem de modo consciente".

Diante do exposto, entende-se que no que se refere ao ensino de Geometria é bastante interessante que o mesmo aconteça de forma interdisciplinar, visto que são muitos os tópicos que podem ser relacionados com outras disciplinas como por exemplo, semelhança de figuras planas, que pode ser abordado em Física, áreas de figuras planas relacionando com a Geografia, entre outros.

Sendo assim, baseado em autores como Zabala (1998), Fazenda (2001), Sommerman (2006), Silva (2008), pode-se afirmar que o ensino na perspectiva interdisciplinar firma-se como uma estratégia eficaz para melhorar o ensino e a aprendizagem, pois ao contextualizar com os outros ramos do conhecimento, os alunos percebem que tal assunto é de fato importante para o seu cotidiano e quanto ao caso da Geometria fica claro que é de fato possível abordá-la nesta perspectiva.

Partindo disso, pode-se chegar ainda numa outra visão pedagógica que chama-se transdisciplinaridade, que defende que o ensino aconteça de maneira aberta e ampla não fazendo ligação com uma ou outra disciplina, ou seja, no caso do ensino de Geometria e suas aplicações as mesmas não devem ser expostas exclusivamente com um olhar matemático (cálculos) ou de qualquer outra disciplina mas de forma a priorizar a interpretação e soluções das situações. Nesse sentido Nicolescu (1999, p. 22), descreve a transdisciplinaridade desse modo:

A transdisciplinaridade como o prefixo 'trans' indica, diz respeito àquilo que está ao mesmo tempo entre as disciplinas, através das diferentes disciplinas e além de 
qualquer disciplina. Seu objetivo é a compreensão do mundo presente para o qual um dos imperativos é a unidade do conhecimento.

Historicamente falando, a expressão transdisciplinaridade foi criada por Jean Piaget no ano de 1970 e desde então a mesma tem se espalhado entre estudiosos e educadores. Como afirma Santana (2010, s.p.):

Esta expressão foi criada pelo educador Jean Piaget, durante o I seminário Internacional sobre Pluri e Interdisciplinaridade, o qual se desenrolou em 1970, na Universidade de Nice, nesta ocasião foi originalmente utilizada esta palavra, deflagrando uma série de pesquisas sobre seu significado e as implicações por traz dessa ideia, estimulada pelo seu criador.

De modo que, aprofundando no conceito de transdisciplinaridade, entende-se que esta visão pedagógica busca acabar com a fragmentação das disciplinas, como afirma D'Ambrosio (1997, p. 9):

\begin{abstract}
A transdisciplinaridade entende que o conhecimento fragmentado dificilmente poderá dar a seus detentores a capacidade de reconhecer e enfrentar situações novas, que emergem de um mundo a cuja complexidade natural acrescenta-se a complexidade resultante desse próprio conhecimento.
\end{abstract}

Portanto, com base nas definições de interdisciplinaridade, transdisciplinaridade e da ligação da Geometria com diversas áreas do conhecimento propõe-se que em conjunto professores de diferentes disciplinas Matemática, Geografia, Física, etc. façam inicialmente um trabalho interdisciplinar com a temática geometria, e depois de terem cada um seus planos de aulas, atividades, exercícios, entre outros materiais contextualizados que os mesmos sejam unificados e organizados, pois assim formar-se-á um único material transdisciplinar a ser colocado em prática em sala de aula pelos mesmos. Desse modo, trabalhando-se este assunto utilizando esse viés pedagógico abordando, por exemplo, interpretação e leitura de gráficos e/ou tabelas, cálculo de áreas e volumes, localização no espaço, etc. não de maneira fechada a uma ou outra disciplina (Matemática, Geografia, etc.), mas sim de forma aberta os alunos sentem-se a vontade de pensar de diferentes formas ampliando-se as ideias e soluções de determinados problemas do cotidiano que até outrora o aluno ficava restrito a buscar respostas por um único caminho, o caminho que uma ou outra disciplina apontava, porém, para isso é necessário que os docentes conheçam essas perspectivas pedagógicas.

\title{
4 APRESENTAÇÃO E ANÁLISE DOS DADOS LEVANTADOS
}

A fim de verificar o que pensam os professores de Matemática sobre o ensino de Geometria e se conhecem e/ou usam a interdisciplinaridade e transdisciplinaridade realizou-se uma pesquisa com os professores de Matemática da Escola Estadual Rafael Godeiro na cidade de Rafael Godeiro/RN, de modo que para a obtenção dos dados, optou-se pela aplicação de questionários em que os sujeitos da pesquisa exporam suas opiniões sobre suas práticas pedagógicas.

Para esta pesquisa, adotou-se a investigação do tipo qualitativa, em que os dados são registrados e interpretados, e a partir deles, tiradas as devidas conclusões, não usando-se para isso 
métodos ou técnicas estatísticas, como média, moda ou desvio padrão. Conforme afirma Galego (2007, p. 49):

\begin{abstract}
As pesquisas qualitativas são exploratórias, ou seja, estimulam os entrevistados a pensarem livremente sobre algum tema, objeto ou conceito. Elas fazem emergir aspectos subjetivos e atingem motivações não explícitas, ou mesmo conscientes, de maneira espontânea. São usadas quando se busca percepções e entendimento sobre a natureza geral de uma questão, abrindo espaço para a interpretação.
\end{abstract}

Os sujeitos da pesquisa foram os 03 professores de Matemática da referida escola, sendo que eles ensinam tanto no Ensino Fundamental II, como Médio e EJA, visto que esta instituição oferece as três modalidades de ensino. Os questionários aplicados ao professores foram divididos em duas partes: na primeira, analisou-se aspectos referentes a sua formação profissional, faixa etária, experiência em sala de aula e escolas em que leciona e na segunda, aspectos relativos ao ensino de Geometria e uso de interdisciplinaridade e transdisciplinaridade.

Do primeiro bloco de questões, constatou-se que os três professores são Licenciados em Matemática, um deles com Especialização em Educação Matemática e lecionam há 7, 8 e 24 anos. No segundo bloco de perguntas põde-se analisar de que maneira estes educadores conduzem suas aulas de Matemática desde o planejamento até a sua execução, verificando que conteúdos são trabalhados, quais as dificuldades encontradas em relação ao ensino de Geometria e se conhecem a interdisciplinaridade e a transdisciplinaridade.

\title{
1. Dentre os campos da Matemática, você prefere?
}

Ao analisar as respostas dos professores, constatou-se que os três afirmaram que preferem o bloco de conteúdos que trata dos "Números e operações". Esta preferência já comprovada por outras pesquisas com maior número de professores, mostra a supervalorização atribuída pelos docentes a alguns tópicos específicos da Matemática como, a Aritmética e a Álgebra, em detrimento de outros, como por exemplo Geometria.

\section{Os alunos mostram interesse pelos conteúdos de Geometria? Como você observa esse interesse?}

Para esta pergunta, o primeiro professor disse que: "Alguns alunos mostram interesse, por causa de conteúdos onde são estudados formas e figuras geométricas na sala de aula"; já o segundo respondeu: "Sim, quando ele é abordado de forma que o aluno relaciona o conteúdo ao seu cotidiano"; e o terceiro afirmou: "Sim, não só de geometria como qualquer outro conteúdo matemático, desde que de forma contextualizada". Diante de tais respostas entende-se que é necessário relacionar os assuntos ministrados com o cotidiano dos alunos.

\section{Em que consistem as dificuldades encontradas na sua prática pedagógica em relação ao ensino de Geometria?}

Para o primeiro professor as dificuldades são: "Associar métodos mais claros de ensino, para que o aluno tenha um desenvolvimento de transformar suas ideias geométricas no cotidiano profissional"; o segundo afirmou: "Consiliar a teoria com a prática, devido não ter material didático suficiente para transmitir o conteúdo de forma prática"; e o último relata: "Na dificuldade de contextualizar conteúdos de geometria espacial". Isso mostra que de fato é preciso novas 
estratégias pedagógicas que facilitem o ensino de geometria, que são de início a interdisciplinaridade e se possível a transdisciplinaridade.

4. O ensino de Geometria é trabalhado em sala de aula no decorrer do ano letivo? Se a resposta for positiva, que tópicos são abordados? Caso seja negativa, especifique o motivo.

5. Na sua opinião, qual a importância da Geometria para o desenvolvimento intelectual do aluno?

6. Em geral, qual o tempo médio que você reserva para o ensino de Geometria no decorrer do ano letivo?

Para este bloco de perguntas o primeiro professor respondeu: "São trabalhados em algumas salas, onde são abordados assuntos relacionados com interesses de mostrar a eles temas da nossa região"; "O aluno se adapta com assuntos que se relaciona com sua concepção para sua vida profissional"; "É uma disciplina que deve ser estudada durante o ano letivo". Como pode-se notar este professor se contradiz um pouco em suas palavras, pois afirma que ensina geometria o ano inteiro, mas só em algumas salas, algo que está errado pois este assunto é abordado em todas os anos/séries da educação básica.

O segundo educador disse: "Sim, geometria plana e geometria espacial"; "A geometria ajuda a desenvolver o raciocinio dos alunos pelo fato de ser mais fácil relacionar a teoria com sua prática cotidiana"; "Um bimestre". E o terceiro docente afirmou que: "Sim. Áreas, volumes, formas, etc."; "Na aquisição da ideia de espaço e forma"; "Em média dois meses".

Percebe-se com estas respostas que estes professores têm trabalhado com seus alunos o assunto Geometria em sala de aula, mas que em nenhum momento se referem a interdisciplinaridade, mostrando que provavelmente ensinam o assunto de maneira fragmentada sem relacionar com as outras disciplinas.

\section{Você já leu, ouviu falar ou estudou sobre interdisciplinaridade?}

Caso sua resposta anterior tenha sido positiva, você acha que a interdisciplinaridade pode melhorar o ensino-aprendizagem de Geometria na educação básica? Comente sua resposta.

Quando questionados sobre o assunto interdisciplinaridade o primeiro professor respondeu que "sim" conhecia o assunto e comentou: "Pode porque existem disciplinas como matemática onde são estudados assuntos relacionados com figuras geométricas e química onde são mostrados em laboratório materiais com peças geométricas".

O segundo entrevistado afirmou que conhecia "bastante" a interdisciplinaridade e completou: "Sim, pelo fato que outras disciplinas podem também abordar o assunto dando mais subsídios para o aluno". E o terceiro disse que "sim" e comentou da seguinte forma: "Sim, pois com o ensino contextualizado e a aplicação dos conhecimentos matemáticos em outras disciplinas, facilita o entendimento". 
Diante destas respostas, percebe-se que pelo fato destes professores conhecerem a interdisciplinaridade, ser possível fazer um trabalho nessa visão pedagógica, associando aos mesmos professores de outras áreas de conhecimento, como, Geografia, Física, Química, etc.

\section{Você já leu, ouviu falar ou estudou sobre transdisciplinaridade?}

9. Caso sua resposta anterior tenha sido positiva, você acha que a transdisciplinaridade pode melhorar o ensino-aprendizagem de Geometria na educação básica? Comente sua resposta.

O objetivo destas últimas perguntas era diagnosticar a possibilidade de realização de um trabalho transdisciplinar nesta escola, sendo que para isso acontecer seria necessário que os docentes entendessem o que é esta perspectiva pedagógica.

Nesse sentido, o primeiro educador respondeu que "não" conhecia a transdisciplinaridade, e consequentemente deixou a última questão em branco. $O$ segundo professor disse que conhecia "um pouco" e comentou: "Sim, pelo fato de você poder abordar essas disciplinas de forma teórica e prática em outros contextos". Já o terceiro afirmou que "sim" e completou: "A transdisciplinaridade é uma expansão da injterdisciplinaridade, melhorando mais e mais a prática do aluno, facilitando a aprendizagem".

Nota-se que, estes docentes não conhcem a transdisciplinaridade, pois o primeiro professor de modo honesto ele próprio confessa e os outros dois pelos seus comentários demosntram que tem apenas uma vaga noção, mas que não condiz com a ideia correta desta visão de ensino. Desta forma, entende-se que apesar de ser desejável, mas mediante a falta de conhecimento do que seja a transdisciplinaridade pelos professores, é bastante difícil colocála em prática, não só nesta escola, mas em muitas da nossa região.

\section{CONCLUSÃO}

O presente trabalho teve como meta priuncipal refletir sobre o ensino de geometria nas perspectivas interdisciplinar e transdisciplinar. Para isso foi feito inicialmente um levantamento bibliográfico, em que foram analisados as opiniões de diversos autores como Lorenzato, Nicolescu e Sommerman que mostraram a eficácia destas visões de ensino.

Nesse sentido, entende-se que apesar de não ser fácil chegar na transdisciplinaridade, propôs-se que diante da temática Geometria, seja feito um trabalho interdisciplinar com professores de diferentes disciplinas, onde cada um abordaria o assunto de forma contextualizada, preparando materiais como planos de aula, exercícios, questões e conteúdos e depois juntaria todos esses materiais a fim de formar um único material de ensino transdisciplinar, contrinuindo para aulas diferentese mais atraentes.

No entanto para que isto possa acontecer, é preciso que os educadores dominem as duas perspectivas pedagógicas, e a fim de constatar tal realidade foi realizada uma pesquisa de campo com professores de matemática de uma escola da rede estadual, onde ficou comprovado que os mesmos conheciam a interdisciplinaridade mas que desconhecem a visão transdisciplinar.

Diante disso, percebe-se que chegar na transdisciplinaridade em muitas escolas ainda é um sonho, algo difícil de ser atingido, porém a interdisciplinaridade é plenamente possível, e é por isso 
que no que se refere ao ensino de Geometria os educadores precisam se conscientizar que precisam procurar desfragmentar o ensino partindo de uma abordagem interdisciplinar na qual faça a ligação entre as várias disciplinas, mostrando como a Geometria e importante não só para a Matemática, mas também pra Geografia, Biologia, Física, etc., e com isso chegar na tão desejável transdisciplinaridade.

\section{REFERÊNCIAS}

1. Ávila, Geraldo. Várias faces da matemática: Tópicos para licenciatura e leitura em geral. 2. ed. São Paulo: Blucher, 2010.

2. BRASIL. Constituição (1988). Constituição da República Federativa do Brasil. Brasília, DF, Senado, 1998.

3.

Decreto lei no 5.622 de 19 de dezembro de 2005 regulamenta o art. 80 da Lei no 9.394, de 20 de dezembro de 1996, que estabelece as diretrizes e bases da educação nacional.

4. - Ministério da educação e cultura. Orientações curriculares nacionais para o Ensino médio. Ciência da natureza, matemática e suas tecnologias. Brasília: SEB, 2006, p. 75,76 .

5 . Lei de Diretrizes e Bases da Educação Nacional - LDB Lei $n^{\circ}$ 9394/96. Disponivel em:< http://portal.mec.gov.br/arquivos/pdf/ldb.pdf>. Acesso em: 20 de novembro de 2013.

6. Parâmetros Curriculares Nacionais: TERCEIRO E QUARTO CICLOS DO Ensino Fundamental/Matemática. Brasília: SEF, 2001.

7. CARTADATRANSDISCIPLINARIDADE. Disponível em<http://www.cetrans.com.br/ textos/documentos/carta-da-transdisciplinaridade.pdf>. Acesso em 15 de agosto de 2014.

8. COSTA, L, M. Unidade 1: Transdisciplinaridade: uma nova visão pedagógica. Material didático do Curso de Especialização em Língua Portuguesa e Matemática numa Perspectiva Transdisciplinar. IFRN: 2013.

9. . Interdisciplinaridade: uma proposta de parcerias entre disciplinas. Disponível em: <http://ead.ifrn.edu.br/moodle/file.php/2479/Aula02ConcEnsMat.pdf> Acesso em: 16 de novembro de 2013.

10. D’AMBROSIO, Ubiratan. Transdisciplinaridade. São Paulo: Palas Athena, 2001.

11. FAZENDA, Ivani C. A. Interdisciplinaridade e Transdisciplinaridade na formação de professores. Disponível em: <http://www.facec.edu.br/seer/index.php/ docenciaepesquisa emadministracao/article/viewFile/9/23>. Acesso em: 15 de outubro de 2013.

12. GALLEGO, Julia Perucchetti. A utilização dos jogos como recurso didático no ensinoaprendizagem da Matemática. Disponível em:< http://www.fc.unesp.br/upload/pedagogia/ TCC\%20Julia\%20Perruchetti\%20-\%20Final.pdf>. Acesso em: 28 de dezembro de 2011.

13. LIBÃNEO, José Carlos \& SANTOS, Akiko. Educação na era do conhecimento em rede e transdisciplinaridade. Campinas, SP: Editora Alínea, 2010. Libertad, 2000 (Cadernos Pedagógicos do Libertad, 2).

14. LORENZATO, Sérgio. Porque não ensinar Geometria? A Educação Matemática em Revista. Blumenau: SBEM, Ano III, n. 4, 1995. 
15. LUCENA, Nedja lima de. Introdução à metodologia do ensino e à interdisciplinaridade. Disponível em:<http://ead.ifrn.edu.br/moodle/file.php/2385/MODULOS/unidade_01__DF.pdf?forcedownload=1> Acesso em: 25 de outubro de 2013.

16. MORIN, E. Introdução ao pensamento complexo. Lisboa, Instituto Piaget, 1991.

17. NICOLESCU, Basarab. O Manifesto da Transdisciplinaridade. Tradução de Lúcia Pereira de Souza. Triom, São Paulo, 1999.

18. NICOLESCU, Basarab. A evolução transdisciplinar da universidade - Condição para o desenvolvimento sustentável. Disponível na Internet: http://perso.clubinternet. $\mathrm{fr} / \mathrm{nicol} /$ ciret/bulletin/12/b12cgpor.htm.

19. OLIVEIRA, L, A. B. Unidade 2: TRANSDISCIPLINARIDADE E COMPLEXIDADE: Similaridades e diferenças entre material didático-pedagógico para as modalidades presencial e a distância. Material didático do Curso de Especialização em Língua Portuguesa e Matemática numa Perspectiva Transdisciplinar. IFRN: 2013.

20. PASSOS, Cármem L. B. Representações, interpretações e prática pedagógica: a geometria na sala de aula. 2000. 348p. Tese (Doutorado em Educação) - Unicamp, Campinas, SP, 2000.

21. SANTANA, Ana Lucia. Transdisciplinaridade. Publicado: 23/11/2010. Disponível em <http://www.infoescola.com/educacao/transdisciplinaridade>. Acesso: 22 de abril de 2014.

22. SEVERINO, Antônio Joaquim. Metodologia do trabalho científico. 22. ed. São Paulo: Cortez, 2004.

23. SILVA, O. S. da. A Interdisciplinaridade na visão de professores de Química do Ensino Médio: Concepções e Práticas. Disponível em: <http:// cienciaematematica.vivawebinter net.com.br/media/dissertacoes/81af424815b46cd.pdf>. Acesso em: 17 de setembro de 2013.

24. SOMMERMAN, Américo. Inter ou transdisciplinaridade?: da fragmentação disciplinar ao novo diálogo entre os saberes. São Paulo: Paulus, 2006.

\section{ANEXO: QUESTIONÁRIO APLICADO AOS PROFESSORES}

Nome: Data:

Escola: Cidade:

Por gentileza, as respostas a este questionário têm como objetivo oferecer subsídios para uma pesquisa sobre o ensino de Geometria numa perspectiva interdisciplinar/transdisciplinar. Entrevistado (formação e experiência)
( ) Apenas Ensino Médio
( ) Licenciado em Matemática
( ) Ensino Superior incompleto
( ) Outras habilitações.

Especifique:

Há quanto tempo leciona?

Faixa etária
( ) $20-29$
( ) $30-39$
( ) $40-49$
( ) $50-60$

Escolas em que leciona? 


\section{QUESTÕES}

01. Dentre os campos da Matemática, você prefere?
( ) Números e operações
( ) Grandezas e medidas
( ) Espaço e formas
( ) Outros

Especificar:

02. Os alunos mostram interesse pelos conteúdos de Geometria? Como você observa esse interesse?

03.Em que consistem as dificuldades encontradas na sua prática pedagógica em relação ao ensino de Geometria?

04. O ensino de Geometria é trabalhado em sala de aula no decorrer do ano letivo? Se a resposta for positiva, que tópicos são abordados? Caso seja negativa, especifique o motivo.

05. Na sua opinião, qual a importância da Geometria para o desenvolvimento intelectual do aluno?

06. Em geral, qual o tempo médio que você reserva para o ensino de Geometria no decorrer do ano letivo?

07. Você já leu, ouviu falar ou estudou sobre interdisciplinaridade?
( ) $\operatorname{sim}$
( ) não
( ) um pouco ( )bastante

08. Caso sua resposta anterior tenha sido positiva, você acha que a interdisciplinaridade pode melhorar o ensino-aprendizagem de Geometria na educação básica? Comente sua resposta.

09. Você já leu, ouviu falar ou estudou sobre transdisciplinaridade?
( ) $\operatorname{sim}$
( ) não
( ) um pouco ( )bastante

10. Caso sua resposta anterior tenha sido positiva, você acha que a transdisciplinaridade pode melhorar o ensino-aprendizagem de Geometria na educação básica? Comente sua resposta. 